to a uniform electron and positive ion high temperature enclosure, and preliminary results indicate that by its means many spectral and chemical problems may be attacked under conditions not previously realisable. The conditions of excitation are probably similar to those existing in the outer atmosphere of the sun.

JAMES TAYLOR.

Trinity College, Cambridge. WILFRID TAYLOR. Jan. 12.

\section{Subsidiary Rectangles as applied to the Formation of Magic Squares.}

IN the issue of Nature of Jan. $14 \mathrm{I}$ gave the smallest 'associated' rectangle, consisting of 3 rows which has the property of the diagonals one way summing to the same as the rows. This was with nonconsecutive numbers. The smallest associated rectangle with consecutive numbers is :

$\begin{array}{rrrrrrrrr}18 & 20 & 24 & 9 & 5 & 12 & 25 & 7 & 6 \\ 2 & 1 & 15 & 17 & 14 & 11 & 13 & 27 & 26 \\ 22 & 21 & 3 & 16 & 23 & 19 & 4 & 8 & 10\end{array}$

In this associated rectangle, the rows and the diagonals from left to right sum to 126 , the columns to 42 . But as with order 18 rectangles $6 \times 3$ the diagonal requirement is not necessary as associated pandiagonals with subsidiary rectangles $9 \times 3$ can be made otherwise.

This diagonal requirement is necessary for all associated pandiagonals with subsidiary rectangles of 3 rows, except as above, when the number of columns in the rectangle is a multiple of the number of rows (three), such as. $6 \times 3,9 \times 3$, etc. With pandiagonals not associated consisting of subsidiary rectangles of 3 rows it is still necessary with all rectangles with an odd number of columns such as $7 \times \mathbf{3 , 5} \times \mathbf{3}$, etc. I give an example of each :

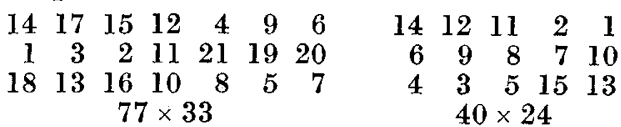

These are with consecutive numbers and not associated. Rectangles with an even number of columns do not require the diagonals one way to sum to the same amount as the rows. Pandiagonal squares can be made by other methods. Such are $4 \times 3,8 \times 3$, etc.

Barkston, Grantham, Lincs. J. C. Burnett.

\section{Production of Bubbles of Selenium.}

IT may be of interest to record that bubbles of selenium can be blown from the end of a suitably shaped glass tube, after dipping it momentarily into the molten "metal."

I find it best to use for this purpose a glass tube which has an internal diameter of about an eighth of an inch, and to bell out slightly the extremity which is to be dipped into the molten selenium.

The temperature of the selenium should be just below that at which it gives off a faint cloud of condensing vapour. By paying attention to these conditions, I have succeeded in blowing bubbles, usually somewhat irregular sausage-shaped things, as long as five centimetres, and three centimetres in diameter at the largest part.

The walls of these bubbles are extremely thin and show well the beautiful rich colour of selenium when viewed by transmitted light. The method also affords a simple means of obtaining small thin flakes of selenium for various experimental purposes.

Great care is required to regulate the air pressure, which only seems to be possible by blowing with the mouth. Success is obtained only by choosing the right moment when the selenium is so far cooled as to be highly viscous.

An interesting property of these bubbles is that if, even after twenty-four hours, they are brought into very light contact with one another, they seize violently together and cannot be again separated.

Charles E. S. Phinlips.

Castle House, Shooter's Hill, S.E.18, Jan. 19.

\section{Inflammable Gas from Plants.}

IN reply to Prof. Findlay's request in Nature of Jan. 14, for information concerning the exhalation of an inflammable gas from the Fraxinella, I have much pleasure in communicating the following items :

(1) From page 336 of vol. 2 of "Chemical Essays," by Dr. R. Watson, Third Edition (London, 1784):

" Fraxinella is a very odorous plant; when in full blossom, the air which surrounds it in a still night may be inflamed by the approach of a lighted candle ; does this inflammability proceed from an inflammable air, which is exhaled by the plant, or from some of the finer particles of the oil of the plant, being dissolved in the common air of the atmosphere."

(2) From page 107 of vol. 1 of " Elementary Lectures on Chemistry and Natural History." Translated from the French of M. Fourcroy (Edinburgh, 1785):

"The atmosphere which floats round the fraxinella is inflammable from the admixture of some essential oil : and M. Scheele is of opinion that every inflammable air is composed of a very subtile oil."

(3) From " Webster's New International Dictionary of the English Language" (London, 1919):

"Fraxinella. A perennial rutaceous herb (Dictamnus albus) with pinnate leaves and white flowers, which exhale an inflammable vapour in hot weather - often called 'gas plant."

The Tower House,

Fredk. C. Short.

Sutton Road, Walsall, Staffs, Jan. 14.

\section{'Self-Adaptation' in Biology.}

"Paracelsus, the first materialist, proclaimed man to be a chemical compound" (NATURE, Jan. 7, p. 14). No doubt Dr. Fournier d'Albe can give references to confirm this statement. In the meantime may I quote the following detached paragraphs ?

"The life of man is an astral effluvium or a balsamic impression, a heavenly and invisible fire, an enclosed essence of spirit. . . ." ("De Natura Rerum," p. 81; Hartmann's "Paracelsus"). "Man has two spirits, a divine and a terrestrial spirit" ("De Lunaticis," ibid. p. 82). "Neither the external nor the astral man is the real man; the real man is the spiritual soul in connection with the divine spirit" ("De Fundamento Sapientiæ," ibid. p. 87). ". . . the organs of the body and the body itself are only formmanifestations of previously and universally existing mental states" ("De Viribus Membrorum," ibïd. p. 219).

"Man is an instrument through which all the three worlds-the spiritual, the astral, and the elementary world-are acting. In him are beings from all these worlds, reasonable and unreasonable, intelligent and unintelligent creatures. A person without selfknowledge and self-control is made to act according to the will of these creatures" ("De Meteoris," ibid. p. 119).

W. W. L.

Jan. 9. 